ORIGINAL ARTICLE

\title{
The relationship of alcohol use and physical activity from an ecologic perspective
}

\author{
April Bigelow, Antonia Villarruel, and David L. Ronis \\ April Bigelow, PhD, ANP-BC, is Clinical Assistant Professor; Antonia Villarruel, PhD, RN, FAAN, is Professor, Nola J. Pender Collegiate Chair and Associate \\ Dean for Research and Global Affairs; and David L. Ronis, PhD, is Research Scientist, Director of Statistical Consulting Team, School of Nursing, University \\ of Michigan, Ann Arbor, Michigan, USA
}

\section{Search terms}

Adolescent, alcohol use, ecologic model, physical activity, predictor.

\section{Author contact \\ aballard@umich.edu, with a copy to the Editor; roxie.foster@ucdenver.edu \\ Acknowledgment \\ No external or intramural funding was received. \\ Disclosure: The authors report no actual or potential conflicts of interest. \\ First Received October 14, 2012; Final Revision received May 23, 2013; Accepted for publication May 24, 2013.}

doi: 10.1111/jspn.12044

\begin{abstract}
Purpose. To determine the predictors of alcohol use (AU) and their relationship to physical activity (PA) among adolescents and to examine differences among groups using an ecologic model.

Design and Methods. Cross sectional secondary analysis of 11,432 adolescents ( $51 \%$ 8th and $49 \%$ 10th graders).

Results. Attitude, perception of risk, and academic performance were the strongest predictors of AU. PA did not moderate, but it had a positive influence on AU in 10th graders. Differences were observed among groups.

Practice Implications. Nurses can address individual and school factors in an effort to decrease AU and guide nurses in creating an individualized plan.
\end{abstract}

Behaviors and practices that begin in adolescence are cemented by adulthood and may have an impact on the development of chronic disease. Evaluation of one specific risk factor, alcohol use (AU), and its relationship to a protective factor, physical activity (PA), may provide insight into adolescent behavior. While both AU and PA have been studied separately in adolescents, minimal research has examined their relationship and mutual influence (Arthur, Hawkins, Pollard, Catalano, \& Bagioni, 2002; Bachman et al., 2008; Jessor, 1991; Johnston, O'Malley, Bachman, \& Schulenberg, 2011; Nelson \& Gordon-Larsen, 2006; Pate, Heath, Dowda, \& Trost, 1996; Patrick \& Schulenberg, in press; Werch et al., 2003). In fact, the current body of research offers contradictory theories and relationships, which indicate a need for further study. Despite recommendations and guidelines to decrease AU and increase PA, the Centers for Disease Control and Prevention (CDC) still report that the majority $(74.3 \%)$ of adolescents have had at least one drink on one or more occasions in the past month (Eaton et al., 2006a, 2008). Additionally, almost half $(43.3 \%)$ reported at least one alcoholic drink in the previous month. Moreover, a quarter of adolescents $(25.5 \%)$ reported drinking five or more alcoholic beverages in a row within the preceding 30 days. While the prevalence of drinking increases with age, an alarming $75 \%$ of high schoolers have tried alcohol at least once (Eaton et al., 2006a, 2006b, 2008).

In contrast, PA rates have declined over the years despite efforts aimed at increasing PA among adolescents. In 2007, $65.3 \%$ of adolescents had not met the current recommendation of PA for 60 min per day on at least 5 out of the last 7 days (CDC, 2006; Eaton et al., 2006b, 2008). Furthermore, only $27.8 \%$ of girls received the recommended daily PA, while $43.8 \%$ of boys met the guidelines. National recommendations for PA continue to increase since research suggests that more people participate in PA when recommended levels are higher (Jeffery, 
Wing, Sherwood, \& Tate, 2003). However, these increased recommendations have not had the desired effect among adolescents. Informed by an ecological perspective, the purpose of this study is to examine predictors of AU and its relationship to PA in adolescents and assess for differences based on gender, grade, and ethnicity.

\section{PHYSICAL ACTIVITY AND ALCOHOL USE}

The relationship between PA and AU is not well understood. While a number of studies have found higher levels of PA to be associated with lower consumption of alcohol (Denver et al., 2012; Patrick \& Schulenberg, in press; Terry-McElrath, O'Malley, \& Johnston, 2011), others have found a positive relationship between $\mathrm{PA}$ and $\mathrm{AU}$ (Bachman et al., 2008; Buscemi, Martens, Murphy, Yurasek, \& Smith, 2011; Peltzer, 2010). These conflicting results indicate that PA may offer a protective effect on risk behavior, but more study is needed to determine other factors in this complex relationship.

Most studies found that as age increases, AU increases, and PA declines (Harris, Gordon-Larsen, Chantala, \& Udry, 2006; Singh, Mahashwari, Sharma, \& Anand, 2006). Therefore, not only are adolescents at increased risk for obesity and cardiovascular disorders related to low PA, they may be at risk for liver dysfunction and electrolyte imbalance due to the effects of alcohol. While studies have attempted to explain the relationship between alcohol, PA, and other correlates, findings are not congruent between studies, and few studies have examined the potential protective effect of PA on AU.

In one study that examined drinking behaviors according to their level of sport involvement, athletes participated more in drinking behavior than those who were more sedentary (Rainey, McKeown, Sargent, \& Valios, 1996). Rates of general alcohol consumption as well as binge drinking were higher in the athlete groups than the sedentary groups of adolescents. In contrast, participation in sports has also been associated with adolescent personality traits that tended to be resistant to alcohol use (Kirkcaldy, Shephard, \& Siefen, 2002). These conflicting results indicate a need for additional research aimed at identifying the unique relationship between AU and PA.

Ethnicity has also been identified as a potential risk or protective factor in adolescents. A strong Mexican American identity was significantly associ- ated with general $\mathrm{AU}(\mathrm{AOR}=.97)$ and heavy drinking $(\mathrm{AOR}=.98$; (Love, Yin, Codina, \& Zapata, 2006). Those adolescents who had strong Mexican American identity were more likely to also report higher AU and heavy drinking. Adolescents who were Caucasian or Asian had the lowest risk of unhealthy behaviors, while Native Americans had the highest risk (Harris et al., 2006). Caucasians, however, experienced the greatest declines in healthy behaviors when monitored into adulthood (Harris et al., 2006). While interesting, the implications of these results are unclear. Observed differences may be related to genetic, social, and/or environmental influences. In many studies, African American and Hispanic adolescent subgroups reported less PA (Eaton et al., 2006b; Gordon-Larsen, Adair, \& Popkin, 2002; Gordon-Larsen, McMurray, \& Popkin, 2000; Harris et al., 2006; Taylor et al., 1999; Whaley $\&$ Francis, 2006) and more AU than Caucasian subgroups (Elder, Leaver-Dunn, Wang, Nagy, \& Green, 2000; Rodriguez \& Audrain-McGovern, 2005; Thorlindsson \& Vilhjalmsson, 1991). However, race or ethnicity may not always explain a significant amount of the variance in AU or PA (Ammouri, Kaur, Neuberger, Gajewski, \& Choi, 2007; Sallis, Prochaska, Taylor, Hill, \& Geraci, 1999; Trost, Pate, Ward, Saunders, \& Riner, 1999).

\section{ORGANIZING FRAMEWORK AND LITERATURE REVIEW}

The Ecological Model of Adolescent Health Risk Behavior is the organizing framework for this research. Originally influenced by Bronfenbrenner's Ecological Systems Model (Bronfenbrenner, 1979), the current Ecological Model has evolved to include five domains of influence over adolescent behavior (Blum, McNeely, \& Nonnemaker, 2001). Individual, social, family, and school contexts along with the macro-level environment all play a role in influencing health risk behaviors or positive health behaviors. In this study, the individual context is conceptualized as attitude toward AU, perception of AU risk, risk-taking behaviors, religious identity, and work behavior; the social context is conceptualized as access to alcohol, peer influence, television use, and neighborhood safety; the family context consists of parental support and perceived parental presence; the school context is defined as academic performance, school attachment, and perceived school safety. 


\section{Individual context}

The individual context is composed of those biological, psychological, and social attributes that influence individual behavior. In this study, the individual context is conceptualized as attitude toward AU, perception of alcohol risk, risk-taking behaviors, religious identity, and individual work behavior. Adolescent attitudes toward alcohol influence individual AU. These attitudes are also influenced by the perceived risks of AU, risk-taking behavior, AU of peers, and the perceived subjective norms. As expected, adolescents who perceive harmful effects from AU are more likely to abstain from drinking (Robinson et al., 2006).

\section{Social context}

The social context, which includes both the immediate or built environment and the social environment, has the potential to influence PA and AU in a variety of ways. The immediate or built environment is defined as access to parks and alcohol, neighborhood safety, and living surroundings. The social context can affect adolescent behaviors directly or indirectly by influencing attitudes, beliefs, or social norms (Cohen, Scribner, \& Farley, 2000). In this study, the social context consists of access to alcohol, peer influence, television use, and neighborhood safety.

Peer groups play a special role during adolescence. The peer group has influence on cognitive processes as well as behavior through modeling (Zambon, Lemma, Borraccino, Dalmasso, \& Cavallo, 2006). Peer influence is so strong in fact that peer behavior has a direct positive effect on drinking behavior (Plotnikoff, Bercovitz, Rhodes, Loucaides, \& Karunamuni, 2007; Wu \& Pender, 2002). Those adolescents who had friends who engaged in risky behaviors, such as drinking, were more likely to participate in risky behaviors (Hawkins, Catalano, $\delta$ Miller, 1992; Reininger et al., 2005). In fact, self and peer values regarding risk behaviors explained $29-44 \%$ of the variance in aggregate risk (African American females $=29 \%$, White females $=40 \%$, African American males $=28 \%$, White males $=44 \%$; Reininger et al., 2005).

\section{Family context}

Family context and family interactions are important throughout adolescence. The family context is defined as the social environment in which the adolescent was raised or spends a great deal of time. In this study specifically, the family context is defined as parental support and parental presence. Family support has been linked to drinking behavior in adolescents. Perceived support from parents has been shown to have a significant negative effect on drinking and other substance use (Walker, Ainette, Wills, \& Mendoza, 2007). Furthermore, family conflict, poor family bonding, and lack of consistent discipline were associated with higher risk of drinking and substance use (Hawkins et al., 1992; Wang, Matthew, Bellamy, \& James, 2005).

\section{School context}

The school is another area that has elicited much research related to PA and AU. The school context is conceptualized as the environment and influencing factors in a place of formalized education and, in this study, consists of academic performance, school attachment, and school safety. In general, higher academic achievement and higher grades are associated with less drinking (Patrick \& Schulenberg, 2010; Belcher \& Shinitzky, 1998; Gau et al., 2007), while academic failure or low academic achievement is correlated with an increased risk of AU (Cox, Zhang, Johnson, \& Bender, 2007; Hawkins et al., 1992).

School connectedness or attachment, or participation in the school community and resources, enjoyment of school, and the belief that school is interesting and important, is another concept within the school context that influences adolescent behavior (Wang et al., 2005). Being active in school has been associated with less engagement in risky behaviors (Nelson \& Gordon-Larsen, 2006; Patrick \& Schulenberg, 2010). In contrast, school disengagement, or lack of participation, was found to be associated with an increased risk of $\mathrm{AU}$ and other risky behaviors (Kliewer \& Murrelle, 2007).

PA and AU are important issues in adolescence. The majority of studies have focused separately on these two phenomena. PA is a health-promoting behavior, and research needs to examine its relationship with other health protective factors and risk behaviors. Furthermore, ecologic models are seldom used as frameworks for adolescent risk and health behavior. The purpose of this study is to examine the relationship of PA to AU in a nationally representative adolescent population. This study has three aims: (a) to identify the individual, 
social, family, and school predictors of AU in adolescents, (b) to determine if there are statistical interactions (moderation) between PA and individual, social, family, or school factors in their effects on AU, and (c) to examine differences by gender, grade, and ethnicity.

\section{METHODS}

This was a cross-sectional secondary analysis using the Monitoring the Future (MTF) database, a nationally representative survey sample of the middle and high school population of the United States (Johnston, Delva, \& O'Malley, 2007). The MTF project was initially established to examine and study changes in the beliefs, attitudes, and behavior of young people in the United States. This project mainly reports on drug and alcohol use in American youth and attempts to explore the direction and rate of change over time. Four different survey forms are used in the national data collection. Only data collected from 8th and 10th graders in 2004 were used to assure consistency of questions across groups as many different versions of the questionnaire existed. These two grades were also selected to assess for any potential differences between ages. The total sample size was 11,422 (8th grade, $n=5,816 ; 10$ th grade, $n=5,606$ ). This study was approved by the institutional review board of the University.

\section{Measures}

Empirical measures related to the following contexts are described: social, school, family, and individual (Figure 1). All measures were self-report and utilized 3- to 7-point Likert scales. Alcohol use was a dependent variable. It was measured by seven questions that asked adolescents if they had ever drunk alcohol or engaged in binge drinking and the frequency of use in the past 30 days and 12 months (Cronbach's alpha $=.84$ for 8 th grade, .89 for 10th grade). The mean score of the seven AU questions was used to create an AU variable. Alcohol users were defined as those adolescents who drank any amount of alcohol or who self-identified as a "regular user." Physical activity was entered as an independent variable as well as within interaction terms to test for moderation. A combined general PA score was created by taking the mean of the two item responses that examined participation in leisure time PA and organized school sports (Cronbach's alpha $=.68$ for 8 th graders, .75 for 10 th graders). The PA score was then transformed into sedentary and

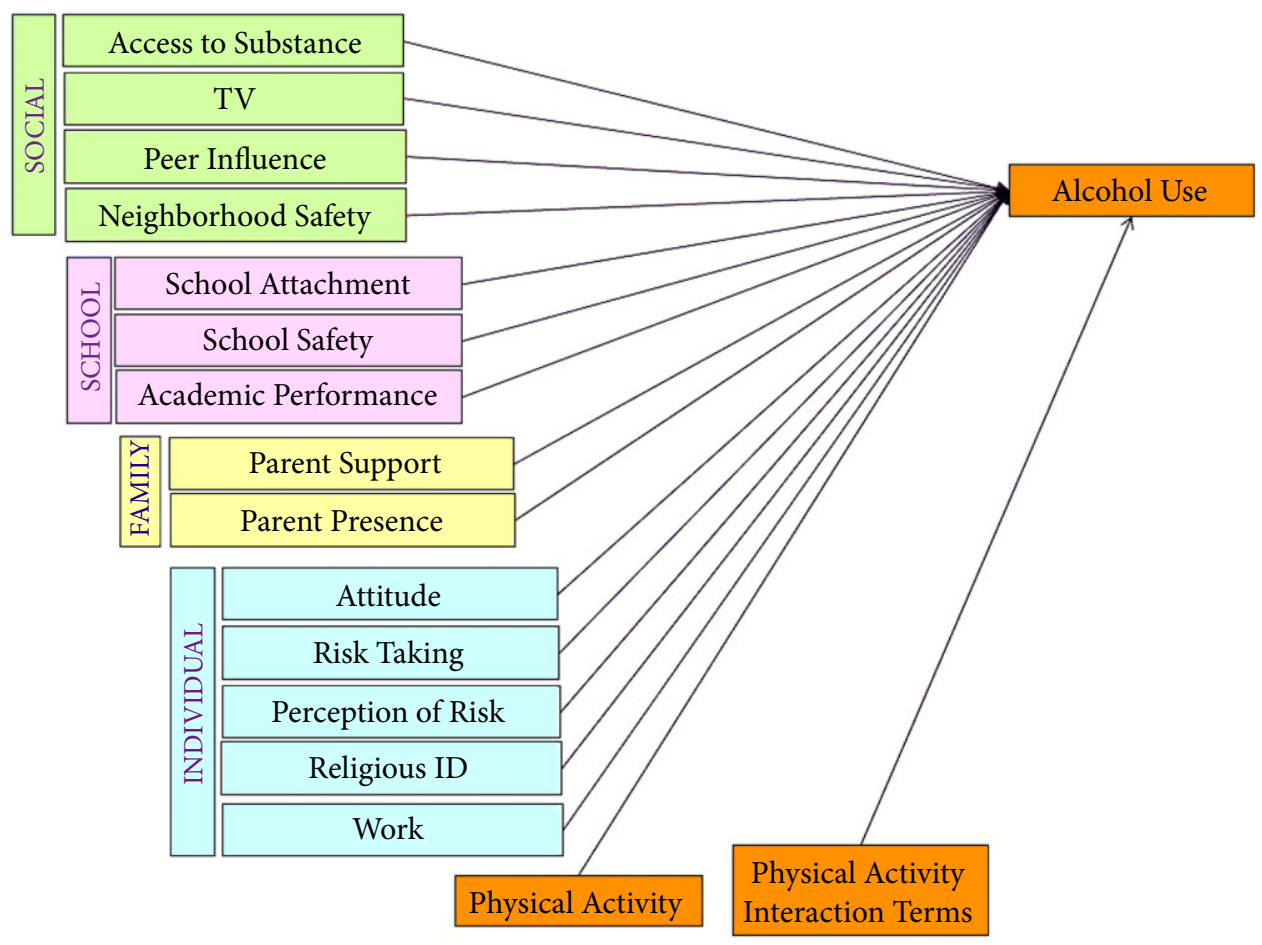

Figure 1 Model of Risk and Protective Factors, Physical Activity, and Alcohol Use. 
high activity groups based on natural breaks in the data and national guidelines and recommendations (U.S. Department of Health and Human Services, 1999).

Independent variables within the individual context were attitude toward alcohol (two items, Cronbach's alpha $=.89$ for $8^{\text {th }}$ grade, .87 for $10^{\text {th }}$ grade), perception of alcohol risk (two items, Cronbach's alpha $=.88$ for $8^{\text {th }}$ grade, .87 for 10 th grade), risk-taking propensity (two items, Cronbach's alpha $=.79$ for 8 th grade, .80 for 10 th grade), religious identity (two items, Cronbach's alpha $=.75$ for 8 th grade, .77 for 10th grade), and work (one question). Independent variables within the social context were access to alcohol (one question), television use (two items, Cronbach's alpha $=.74$ for 8 th grade, .76 for 10th grade), peer influence (one item), and perceived neighborhood safety (one item). The family context was comprised of parental presence (one item) and parental support (two items, Cronbach's alpha $=.65$ for 8 th grade, .62 for 10 th grade). Finally, the school context was comprised of school attachment (three items, Cronbach's alpha $=.77$ for 8 th grade, .76 for 10th grade), school safety (seven items, Cronbach's alpha $=.79$ for 8 th grade, .78 for 10th grade), and academic performance (six items, Cronbach's alpha $=.67$ for 8 th grade, .66 for 10 th grade).

\section{Analysis}

Descriptive statistics were used to characterize sample characteristics. Multiple regression was used to analyze independent and dependent variables. Regression analyses were conducted using SPSS software (http://www-01.ibm.com/software/analytics/ spss/). Data analysis was conducted in a series of steps. First, regression analyses were run with AU as the dependent variable. All predictors were entered together. To test for the moderating effects of PA, interaction terms were created between PA and each of the potential predictors and re-entered into the regression equation as independent variables using the procedures of Baron and Kenny (1986). Finally, differences by gender and ethnicity were assessed using Student's $t$-tests. To adjust for the large number of tests, results were considered significant at the $p<$ .001 level, which is equivalent to alpha of .05 with a Bonferroni adjustment for 50 significance tests. Regression models were re-run within specific demographic subgroups. Data were weighted for all analyses. Multicollinearity was tested using variation inflation factors, which were all less than .5.

\section{RESULTS}

\section{Demographics}

Of the total 11,432 adolescents selected for this study, approximately $51 \%$ were 8 th grade students at the time of survey $(n=5,826)$, and $49 \%$ were 10th grade students $(n=5,606)$. In the 8 th-grade sample, males and females were equally represented $($ males $=48.9 \%$, females $=48.3 \%)$. The majority of the sample was Caucasian (59.9\%), followed by Hispanic (14.7\%), and African American $(11.1 \%)$. More than three quarters of the sample lived in a city or town $(75.7 \%)$. Almost half of the students were enrolled in a college preparatory program or general high school $(31.6 \%, 17.4 \%$, respectively). The majority of the students did not work for money outside of the home (65.9\%). Twenty-nine percent of 8 th graders did not participate in organized athletics, while more than half $(55.2 \%)$ reported that they got some form of daily exercise.

The 10th-grade sample had similar demographics. Most adolescents were Caucasian (61.3\%), followed by Hispanic (15.6\%) and African American $(12.6 \%)$. Nearly $80 \%(77.6 \%)$ lived in cities or towns. Most of the students were enrolled in a college preparatory program $(47.3 \%)$ or general high school $(23.8 \%)$. Most students did not have a job outside of the home $(63.4 \%)$ or worked 5 or fewer hours per week (12.0\%). Thirty-five percent of students participated in organized athletics, while half $(50.4 \%)$ reported that they got some form of daily exercise. Nearly half of 8 th graders $(42.9 \%, n=2,500)$ and more than half of 10 th graders $(63.4 \%, n=3,549)$ reported having ever consumed alcohol.

\section{Predictors of alcohol use}

In the 8th-grade sample attitude toward alcohol, propensity for taking risks, perceived risk of alcohol, work hours, access to alcohol, peer pressure to drink, parental presence, parental support, school safety, and academic performance emerged as significant predictors of AU $(p<.001$; Figure 2$)$. In the 10th-grade sample, the above predictors were also significant, in addition to religious identity, television use, and PA. The strongest predictors for both 8th and 10th grade groups were attitude toward alcohol (8th $B=-.115$, 10th $B=-.255)$, perceived risk of $\mathrm{AU}$ (8th $B=-.170,10$ th $B=$ -.163 ), and academic performance (8th $B=-.162$, 


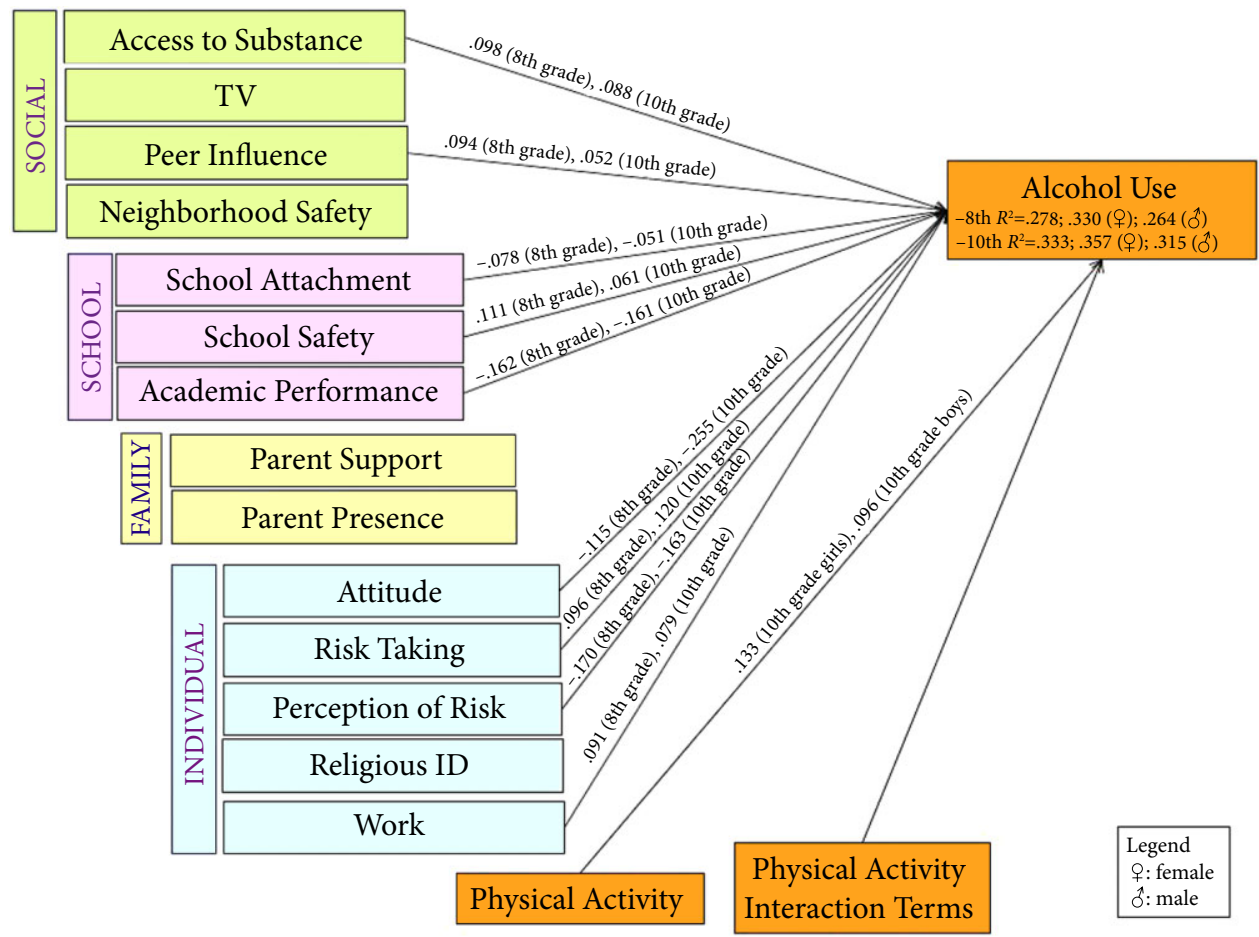

Figure 2 Significant Predictors of $\mathrm{AU}(p<.001)$.

$10 \operatorname{th} B=-.149$ ). PA was not a significant predictor of $\mathrm{AU}$ in the 8th-grade sample. In the 10th-grade sample, however, PA was a small, but significant, predictor of AU in boys $(B=.096)$ and girls $(B=$ $.133)$. In the 8th-grade sample, the model explained nearly $28 \%\left(R^{2}=.278\right)$ of the variance in $\mathrm{AU}$, and for 10th graders, a third $\left(R^{2}=.333\right)$ of the variance was explained.

\section{Moderating effects of physical activity}

In the 8th-grade sample, the product term testing interaction between PA and television use had a significant effect on AU, indicating that PA moderates the effect of television watching on AU $(t(28)=$ $4.096, p<.001)$. Increased television use was associated more strongly with less AU among those who reported more PA. No interaction terms were significant in the 10th-grade sample. Based on natural breaks in the data, physical activity was also divided into two groups. In the sedentary activity group, the model predicted $25.8 \%$ of the variance in AU in 8th grade and $31.3 \%$ of the variance in 10 th grade. In the high activity group, the model explained 34.3\% of the variance in the 8th-grade group and $38 \%$ of the variance in the 10th-grade group.

\section{Differences between groups}

Gender. Independent $t$-tests identified many significant differences in means in both 8th grade and 10 th grade. In 8 th grade, significant differences were found between males and females in perceived access to alcohol, television, neighborhood safety, school attachment, school safety, academic performance, parental support, risk-taking propensity, and work. In the 10th-grade group, the only variables that were nonsignificant were attitude, access to alcohol, peer influence, parent support, and parental presence; all other variables were significant. Eighth grade boys reported more PA than girls $(t[4869]=5.893, p<.001)$, but no significant differences were observed in AU. In the 10th-grade sample, boys were also more physically active $(t[5228]=9.030, p<.001)$ but also reported more AU than girls $(t[4995]=3.787$, $p<.001)$.

Several variables were significant predictors of AU although the amount of influence of each was small. In 8th-grade girls' attitude, risk taking, perceived alcohol risk, work hours, access to substance, peer pressure to drink, parent presence, 
school safety, and academic performance were significant predictors of AU. The strongest predictors of AU were attitude $(B=-.175)$, risk taking $(B=.155)$, and academic performance $(B=-.173)$. For 8th-grade boys, perception of alcohol risk $(B=-.197)$, work hours $(B=.129)$, school safety $(B=.124)$, and academic performance $(B=-.159)$ were the strongest predictors of AU. In 10th-grade girls, the strongest predictors of use were attitude $(B=-.261)$, risk taking $(B=.145)$, alcohol risk $(B=-.182)$, and academic performance $(B=$ -.139 ). For 10th-grade boys, all variables were significant predictors of AU use except television viewing, neighborhood safety, and school attachment. The strongest predictors were attitude toward alcohol $(B=-.261)$, perceived risk of alcohol $(B=-.144)$, and academic performance $(B=-.161)$. This was the only group in which PA was significantly predictive of AU $(B=.096)$.

The proposed model explained $26 \%$ of the variance $\left(R^{2}=.264\right)$ of $\mathrm{AU}$ in 8 th-grade boys. In 10th-grade boys, $31 \%$ of the variance was explained $\left(R^{2}=.315\right)$. In 8 th-grade girls, $33 \%$ of the variance $\left(R^{2}=.330\right)$ in alcohol use was explained by the model, while nearly $36 \%$ of the variance $\left(R^{2}=.357\right)$ was explained by the model in 10th-grade girls.

Ethnicity. Independent $t$-tests in the 8th-grade sample revealed no significant differences in AU between Caucasian and African American respondents. Hispanics reported more AU $(t[4050]=$ $-4.327, p<.001)$ than Caucasians and African Americans $(t[3981]=-3.0909, p<.001)$. Similar results were observed in the 10th-grade sample. Caucasians reported more drinking than African Americans $(t[3820]=6.729, p<.001)$. Likewise, Hispanics reported more AU than African Americans $(t[1220]=-7.320, p<.001)$. No significant differences in AU were seen between Caucasians and Hispanics.

In 8th-grade African Americans, the proposed model explained nearly $27 \%\left(R^{2}=.268\right)$ of the variance in AU. The strongest predictors of AU in 8thgrade African Americans were perceived school safety $(\beta=.186)$ and attitude $(\beta=-.297)$. In 10thgrade African Americans, $25 \%\left(R^{2}=.254\right)$ of the variance was explained, and the strongest predictor of AU was attitude $(\beta=-.189)$. In Hispanics, the model predicted $28 \%\left(R^{2}=.281\right)$ of the variance in 8th graders and $35 \%\left(R^{2}=.355\right)$ of the variance in 10th graders. In Hispanics, the strongest predictors of $\mathrm{AU}$ were risk-taking propensity (8th grade $\beta=$ $.341,10$ th grade $\beta=.171$ ) and perception of alcohol risk (8th grade $\beta=-.262,10$ th grade $\beta=-.241$ ). In 10th-grade Hispanics' attitude toward alcohol was a significant negative predictor of AU $(\beta=-.220)$. In Caucasian groups, the model accounted for $31 \%$ $\left(R^{2}=.316\right)$ of the variance in the 8th-grade group and $36 \%\left(R^{2}=.360\right)$ of the variance in the 10thgrade group. In 8th-grade Caucasians, the strongest predictors of AU were perception of alcohol risk $(\beta=-.221)$ and risk-taking propensity $(\beta=.320)$. In Caucasian 10th graders, the strongest predictors of AU were perception of alcohol risk $(\beta=-.153)$ and attitude $(\beta=-.301)$.

\section{DISCUSSION}

The purpose of this study was to examine the relationship of risk and protective factors of AU in adolescents using an ecologic model as an organizing framework. The model explained a significant amount of variance in $\mathrm{AU}$ in both 8th-grade $(28.1 \%)$ and 10 th-grade $(33.2 \%)$ groups. While the variance explained is moderate, analysis by gender and grade produced interesting results. The model explained the most variance in AU in 10th-grade Caucasian adolescents (36\%), 10thgrade Hispanics $(35.5 \%)$, and 10th-grade females $(35.7 \%)$. These differences may be due to the fact that other non-tested variables play a greater predictive role in adolescent AU for other subgroups.

The strongest predictors of AU were within the individual and school contexts. The family context variables were not as strong as findings in previous research. Academic performance was a significant predictor in all models tested. As with previous research, higher academic performance had direct negative effects on AU (Cox et al., 2007; Schmitz et al., 2002). School safety was consistently positively related to $\mathrm{AU}$, regardless of group. That is to say, higher perceived school safety was related to higher levels of AU. Higher levels of perceived school safety led adolescents to participate in a variety of behaviors, both risk and protective. This notion of school safety and its possible positive influence on alcohol use has not been studied well in the literature. These results indicate that while school safety is a significant variable in adolescent behavior, ensuring or increasing school safety may not have the desired effect on negative behaviors. 
This is one of the first studies to examine PA as a moderator for risky adolescent behavior. PA was not a true statistical moderator, but it did seem to influence AU. Comparisons between squared multiple correlations for PA groups revealed interesting results. The variables in the sedentary activity group predicted $25.8 \%$ of the variance in AU in 8th grade and $31.3 \%$ of the variance in 10 th grade. In the high activity group, $34.3 \%$ of the variance was explained by the model compared to $38 \%$ of the variance in the 10th-grade group. These differences may imply a more complex relationship between PA and AU than simple moderation. The model explained more of the variance in AU with high PA groups (34.3-38.0\%) than with low PA groups $(25.8-31.3 \%)$. This result contradicts the notion that PA may play some protective role against alcohol use. Furthermore, PA positively predicted AU in 10th-grade boys and girls. Those adolescents who reported more PA also reported more AU. While the beta was small given the large sample size, the nature of this relationship warrants further investigation. One possible explanation may be a social or peer influence to drink alcohol on sports teams. Future studies should evaluate the differences between adolescents who are physically active drinkers and nondrinkers and physically inactive drinkers and nondrinkers.

Overall, the Ecological Model of Adolescent Behavior had good fit to the data and explained moderate variance in AU. Individual and school factors emerged as the strongest predictors of behaviors. Differences were observed between males and females, as well as between ethnic groups. While PA did not moderate risk factors in the true statistical definition of the term, differences were observed in AU based on PA level. Thus, further research investigating the role and relationship of PA with other risk and protective factors is warranted.

Adolescence is a time of exploration and influence. Behaviors that are initiated in adolescence have the potential to carry over into adulthood. Nationally, adolescent rates of AU are alarmingly high, while rates of PA are low. An ecological or environmental approach to adolescent behavior research provides insight into potential solutions for these problems. The Ecological Model of Adolescent Behavior can guide practice and research aimed at increasing PA and decreasing substance use. Specifically, research and interventions aimed at the individual and school contexts has the potential to greatly impact adolescent behavior.

\section{How might this information affect nursing practice?}

This study encourages an ecologic model when working with adolescents in an effort to assess the multiple influences during this period. This model challenges nurses to rethink the traditional social ecology and factors that have the potential to influence adolescent behaviors and decisions. While access to alcohol and peer pressure to consume alcohol are commonly thought of as risk factors for $\mathrm{AU}$ in adolescents, increased physical activity may not be recognized as a potential risk factor for alcohol consumption. Using the knowledge that individual and school factors have a strong influence on AU and PA in the adolescent, nurses can focus assessments on these contexts while caring for adolescents.

The study also encourages nurses to consider the interesting relationship behaviors commonly thought of as "risk" and "protective" and their potential complex mutual influence over adolescent health behavior. These results further challenge nurses to consider potential overlaps between an ecologic perspective and adolescent resiliency. Strong connectedness with school was a negative predictor of AU; however, parental support or presence was not significant. Despite the lack of significance in this study, we continue to recommend nurses consider the potential parental influence due to past research that has shown the positive effects of a strong parental relationship.

Nurses are in a unique position to work with patients across the lifespan in a variety of settings. As a trusted member of the healthcare team, nurses are able to assess the adolescent's attitude toward substances and perceived risk of the substance in addition to current practices with AU and PA. Once baseline knowledge and attitudes are established, they can work with adolescents in an effort to decrease AU with unique plans and interventions. Furthermore, nurses can work within the schools to provide education, support, and interventions aimed at increasing PA as well as with parents and adolescents individually. Finally, nurses can work independently or as part of a multidisciplinary team to continue to research the potential relationship between risk and protective factors in this vulnerable age group. 


\section{References}

Ammouri, A. A., Kaur, H., Neuberger, G. B., Gajewski, B., \& Choi, W. S. (2007). Correlates of exercise participation in adolescents. Public Health Nursing, 24(2), 111-120. doi:10.1111/j.1525-1446.2007.00615.x

Arthur, M. W., Hawkins, J. D., Pollard, J. A., Catalano, R. F., \& Bagioni, A. J., Jr. (2002). Measuring risk and protective factors for substance use, delinquency, and other adolescent problem behaviors: The communities that care youth survey. Evaluation Review, 26(6), 575-601. doi:10.1177/019384102237850

Bachman, J. G., O’Malley, P. M., Schulenberg, J., Johnston, L. D., Freedman-Doan, P., \& Messersmith, E. E. (2008). The education-drug connection: How successes and failures in school relate to adolescent smoking, drinking, drug use, and deliquency. Mahwah, NJ: Lawrence Erlbaum Associates.

Baron, R. M., \& Kenny, D. A. (1986). The moderator-mediator variable distinction in social psychological research: Conceptual, strategic, and the statistical considerations. Journal of Personality $\theta$ Social Psychology, 51(6), 1173-1182.

Belcher, B. M. E., \& Shinitzky, H. E. (1998). Substance abuse in children: Prediction, protection, and prevention. Archives of Pediatrics $\theta$ Adolescent Medicine, 152, 952-960. doi:10.1001/archpedi.152.10.952

Blum, R. W., McNeely, C., \& Nonnemaker, J. (2001). Vulnerability, risk, and protection. In B. Fischhoff, E. O. Nightingale, \& J. G. Iannotta (Eds.), Adolescent risk and vulnerability: Concepts and measurement (pp. 50-72). Washington, DC: National Academy Press.

Bronfenbrenner, U. (1979). The ecology of human development: Experiments by nature and design. Cambridge, MA: Harvard University Press.

Buscemi, J., Martens, M. P., Murphy, J. G., Yurasek, A. M., \& Smith, A. E. (2011). Moderators of the relationship between physical activity and alcohol consumption in college students. Journal of American College Health, 59(6), 503-509. doi:10.1080/07448481.2010.518326

Centers for Disease Control and Prevention. (2006). Youth Risk Behavior Survey: United States 2005. Morbidity and Mortality Weekly Report, 55(SS05), 1-108.

Cohen, D. A., Scribner, R. A., \& Farley, T. A. (2000). A structural model of health behavior: A pragmatic approach to explain and influence health behaviors at the population level. Preventive Medicine, 30, 146-154. doi:10.1006/pmed.1999.0609

Cox, R. G., Zhang, L., Johnson, W. D., \& Bender, D. R. (2007). Academic performance and substance use: Findings from a state survey of public high school students. Journal of School Health, 77(3), 109-115. doi:10.1111/j.1746-1561.2007.00179.x

Denver, B. V., Schulenberg, J., Dworkin, J. B., O'Malley, P. M., Kloska, D. D., \& Bachman, J. G. (2012). Predicting risk-taking with and without substance use: The effects of parental monitoring, school bonding, and sports participation. Prevention Science, 13(6), 605-615. doi:10.1007/s11121-012-0288-z

Eaton, D. K., Kann, L., Kinchen, S., Ross, J., Hawkins, J. D., Harris, W. A., . . Wechsler, H. (2006a). Youth risk behavior surveillance-United States, 2005. Atlanta, GA: CDC, USDHHS.

Eaton, D. K., Kann, L., Kinchen, S., Ross, J., Hawkins, J. D., Harris, W. A., . . Wechsler, H. (2006b). Youth Risk Behavior Surveillance: United States 2005. Journal of School Health, 76(7), 353-372. doi:10.1111/j.1746-1561. 2006.00127.x

Eaton, D. K., Kann, L., Kinchen, S., Shanklin, S., Hawkins, J. D., Harris, W. A., . . Centers for Disease Control and Prevention. (2008). Youth risk behavior surveillance-United States, 2007. Morbidity and Mortality Weekly Report, Surveillance Summaries, 57(4), 1-131.

Elder, C., Leaver-Dunn, D., Wang, M. Q., Nagy, S., \& Green, L. (2000). Organized group activity as a protective factor against adolescent substance use. American Journal of Health Behavior, 24(2), 108-1 14.

Gau, S. S., Chong, M. Y., Yang, P., Yen, C. F., Liang, K. Y., \& Cheng, A. F. (2007). Psychiatric and psychological predictors of substance use disorders among adolescents: A longitudinal study. British Journal of Psychiatry: Journal of Mental Science, 190, 42-48. doi:10.1192/bjp.bp.106. 022871

Gordon-Larsen, P., Adair, L. S., \& Popkin, B. M. (2002). Ethnic differences in physical activity and inactivity patterns and overweight status. Obesity Research, 10(3), 141-149. doi:10.1038/oby.2002.23

Gordon-Larsen, P., McMurray, R. G., \& Popkin, B. M. (2000). Determinants of adolescent physical activity and inactivity patterns. Pediatrics, 105(6), e83-e89. doi:10.1542/peds.105.6.e83

Harris, K. M., Gordon-Larsen, P., Chantala, K., \& Udry, J. R. (2006). Longitudinal trends in race/ethnicity disparities in leading health indicators from adolescence to young adulthood. Archives of Pediatrics $\theta$ Adolescent Medicine, 160(1), 74-81. doi:10.1001/archpedi.160.1.74

Hawkins, J. D., Catalano, R. F., \& Miller, J. Y. (1992). Risk and protective factors for alcohol and other drug problems in adolescence and early adulthood: Implications for substance abuse prevention. Psychological Bulletin, 112(1), 64-105. doi:10.1037/ 0033-2909.112.1.64

Jeffery, R. W., Wing, R. R., Sherwood, N. E., \& Tate, D. F. (2003). Physical activity and weight loss: Does prescribing higher physical activity goals improve outcome? American Journal of Clinical Nutrition, 78, 684-689.

Jessor, R. (1991). Risk behavior in adolescence: A psychosocial framework for understanding and action. Journal of Adolescent Health, 12, 597-605. 
Johnston, L. D., Delva, J., \& O'Malley, P. M. (2007). Sports participation and physical education in American secondary schools: Current levels and racial/ethnic and socioeconomic disparities. American Journal of Preventive Medicine, 33(4S), S195-S208. doi:10.1016/j.amepre. 2007.07.015

Johnston, L. D., O'Malley, P. M., Bachman, J. G., \& Schulenberg, J. (2011). Monitoring the future national survey results on drug use, 1975-2010. Volume I: Secondary school students. Ann Arbor, MI: Institute for Social Research, The University of Michigan.

Kirkcaldy, B. D., Shephard, R. J., \& Siefen, R. G. (2002). The relationship between physical activity and self-image and problem behaviour among adolescents. Social Psychiatry \& Psychiatric Epidemiology, 37, 544-550. doi:10.1007/s00127-002-0554-7

Kliewer, W., \& Murrelle, L. (2007). Risk and protective factors for adolescent substance use: Findings from a study in selected Central American countries. Journal of Adolescent Health, 40(5), 448-455. doi:10.1016/ j.jadolhealth.2006.11.148

Love, A. S., Yin, Z., Codina, E., \& Zapata, J. T. (2006). Ethnic identity and risky health behaviors in school-age Mexican-American children. Psychological Reports, 98(3), 735-744. doi:10.2466/PR0.98.3.735-744

Nelson, M. C., \& Gordon-Larsen, P. (2006). Physical activity and sedentary behavior patterns are associated with selected adolescent health risk behaviors. Pediatrics, 117(4), 1281-1290. doi:10.1542/peds.2005-1692

Pate, R. R., Heath, G. W., Dowda, M., \& Trost, S. G. (1996). Associations between physical activity and other health behaviors in a representative sample of U.S. adolescents. American Journal of Public Health, 86(11), 1577-1581. doi:10.2105/AJPH.86.11.1577

Patrick, M. E., \& Schulenberg, J. (2010). Alcohol use and heavy episodic drinking prevalence and predictors among national samples of American eighth- and tenth-grade students. Journal of Studies on Alcohol and Drugs, 71, 41-45.

Patrick, M. E., \& Schulenberg, J. (in press). The burden of alcohol use: Alcohol use among middleand high-school age youth. Alcohol Research and Health.

Peltzer, K. (2010). Leisure time physical activity and sedentary behavior and substance use among in-school adolescents in eight African countries. International Journal of Behavioral Medicine, 17(4), 271-278. doi:10.1007/s12529-009-9073-1

Plotnikoff, R. C., Bercovitz, K., Rhodes, R. E., Loucaides, C. A., \& Karunamuni, N. (2007). Testing a conceptual model related to weight perceptions, physical activity, and smoking in adolescents. Health Education Research, 22(2), 192-202. doi:10.1093/her/cyl065

Rainey, C. J., McKeown, R. E., Sargent, R. G., \& Valios, R. F. (1996). Patterns of tobacco and alcohol use among sedentary, exercising, non-athletic, and athletic youth. Journal of School Health, 66(1), 27-32.

Reininger, B. M., Evans, A. E., Griffin, S. F., Sanderson, M., Vincent, M. L., Valois, R. F., \& Parra-Medina, D. (2005). Predicting adolescent risk behaviors based on an ecological framework and assets. American Journal of Health Behavior, 29(2), 150-161. doi:10.5993/AJHB. 29.2.6

Robinson, L. A., Murray, D. M., Alfano, C. M., Zbikowski, S. M., Blitstein, J. L., \& Klesges, R. C. (2006). Ethnic differences in predictors of adolescent smoking onset and escalation: A longitudinal study from 7th to 12th grade. Nicotine $\theta$ Tobacco Research, 8(2), 297-307. doi:10.1080/14622200500490250

Rodriguez, D., \& Audrain-McGovern, J. (2005). Physical activity, global physical self concept, and adolescent smoking. Annals of Behavorial Medicine, 30(3), 251-259.

Sallis, J., Prochaska, J. J., Taylor, W. C., Hill, J. O., \& Geraci, J. C. (1999). Correlates of physical activity in a national sample of girls and boys in grades 4 through 12 . Health Psychology, 18(4), 410-415. doi:10.1037/0278-6133. 18.4 .410

Schmitz, K. H., Lytle, L., Phillips, G. A., Murray, D. M., Bimbaum, A. S., \& Kubik, M. Y. (2002). Psychosocial correlates of physical activity and sedentary leisure habits in young adolescents: The Teens Eating for Energy and Nutrition at School study. Preventive Medicine, 34, 266-278. doi:10.1006/pmed.2001.0982

Singh, A. K., Mahashwari, A., Sharma, N., \& Anand, K. (2006). Lifestyle associated risk factors in adolescents. Indian Journal of Pediatrics, 73(10), 901-906.

Taylor, W. C., Yancey, A. K., Leslie, J., Murray, N. G., Cummings, S. S., Sharkey, S. A., . . McCarthy, W. J. (1999). Physical activity among African American and Latino middle school girls: Consistent beliefs, expectations, and experiences across two sites. Women $\theta$ Health, 30(2), 67-82.

Terry-McElrath, Y., O'Malley, P. M., \& Johnston, L. D. (2011). Exercise and substance use among American youth, 1991-2009. American Journal of Preventive Medicine, 40(5), 530-540. doi:10.1016/j.amepre. 2010.12 .021

Thorlindsson, T., \& Vilhjalmsson, R. (1991). Factors related to cigarette smoking and alcohol use among adolescents. Adolescence, 26(102), 399-418.

Trost, S. G., Pate, R. R., Ward, D. S., Saunders, R. P., \& Riner, W. (1999). Correlates of objectively measured physical activity in preadolescent youth. American Journal of Preventive Medicine, 17(2), 120-126. doi:10.1016/S0749-3797(99)00056-2

U.S. Department of Health and Human Services. (1999). Physical activity and health: A report from the surgeon general. Atlanta, GA: Government Printing Office.

Walker, C., Ainette, M. G., Wills, T. A., \& Mendoza, D. (2007). Religiosity and substance use: Test of an 
indirect-effect model in early and middle adolescence. Psychology of Addictive Behaviors, 21 (1), 84-96.

doi:10.1037/0893-164X.21.1.84

Wang, M. Q., Matthew, R. F., Bellamy, N., \& James, S. (2005). A structural model of the substance use pathways among minority youth. American Journal of Health Behavior, 29(6), 531-541. doi:10.5993/AJHB. 29.6.8

Werch, C., Moore, M., DiClemente, C. C., Owen, D. M., Jobli, E., \& Bledsoe, R. (2003). A sport-based intervention for preventing alcohol use and promoting physical activity among adolescents. Journal of School Health, 73(10), 380-388.
Whaley, A. L., \& Francis, K. (2006). Behavorial health in multi-racial adolescents: The role of Hispanic/Latino ethnicity. Public Health Reports, 121(2), 169-174.

Wu, T. Y., \& Pender, N. J. (2002). Determinants of physical activity among Taiwanese adolescents: An application of the Health Promotion Model. Research in Nursing and Health, 25, 25-36. doi:10.1002/nur.10021

Zambon, A., Lemma, P., Borraccino, A., Dalmasso, P., \& Cavallo, F. (2006). Socio-economic position and adolescents' health in Italy: The role of the quality of social relations. European Journal of Public Health, 16(6), 627-632. doi:10.1093/eurpub.ckl051 